\title{
Behavioral Reversal of Lithium Effects by Four Inositol Isomers Correlates Perfectly with Biochemical Effects on the PI Cycle:
}

\section{Depletion by Chronic Lithium of Brain Inositol Is Specific to Hypothalamus, and Inositol Levels May be Abnormal in Postmortem Brain from Bipolar Patients}

Robert H. Belmaker, M.D., Galila Agam, Ph.D., Dietrich van Calker, M.D., Ph.D., Mary H. Richards, Ph.D., and Ora Kofman, Ph.D.

The inositol depletion hypothesis of lithium (Li) action has been criticized, because depletion of inositol after chronic $\mathrm{Li}$ treatment has not been reproducible, effects of inositol to reverse Li-induced behaviors occurred also with epi-inositol, a unnatural isomer, and because inositol is ubiquitous in brain and hard to relate to the pathogenesis of affective disorder. Therefore, we review our studies showing that lithium depletion of brain inositol occurs chronically in the hypothalamus, a region not previously examined; that behavioral effects of four different inositol isomers including epi-inositol correlate perfectly with their biochemical effects; and that inositol in postmortem human brain is reduced by $25 \%$ in frontal cortex of bipolars and suicides as compared with controls. Because inositol in postmortem brain is reduced and not increased in bipolar patients, the relationship between inositol, lithium, and affective disorder is complex. [Neuropsychopharmacology 19:220-232, 1998] (C) 1998 American College of Neuropsychopharmacology. Published by Elsevier Science Inc.
KEY WORDS: Inositol; Hypothalamus; Epi-inositol; Myo-inositol; Bipolar disorder; Frontal cortex

Lithium $\left(\mathrm{Li}^{+}\right)$has therapeutic and prophylactic effects on both the manic and depressive phases of bipolar affective disorder; however, the mechanism of Li's therapeutic action is not clear. Several biochemical actions have been attributed to $\mathrm{Li}^{+}$(Wood and Goodwin 1987),

From the Ministry of Health Mental Health Center (RHB, GA, OK), Faculty of Health Sciences Ben Gurion University of the Negev, Beersheva, Israel; Klinikum Der Albert-Ludwigs-Universitat (DvC), Abt Allgemeine Psychiatrie mit Poliklinik, Freiburg, Germany; and Marion Merrell Research Institute (MHR), Strasbourg, France.

Address correspondence to: Professor R.H. Belmaker, Beersheva Mental Health Center, P.O. Box 4600, Beersheva, Israel.

Received February 23, 1998; accepted February 23, 1998. but none has been incontrovertibly associated with its effects on behavior or mood.

$\mathrm{Li}^{+}$inhibits the dephosphorylation of four of the inositol monophosphates as well as two inositol biphosphates, thereby increasing brain levels of inositol monophosphate and two biphosphates and reducing levels of myo-inositol (Allison et al. 1976; Allison et al. 1980; Honchar et al. 1989; Sherman et al. 1981, 1985b). These effects are attributable to $\mathrm{Li}^{+\prime}$ s inhibition of inositol monophosphatase (Hallcher and Sherman 1980; Moscovich et al. 1990) and inositol polyphosphate 1-phosphatase (Inhorn and Majerus 1987). In rats, lithium chloride $(\mathrm{LiCl}), 10 \mathrm{meq} / \mathrm{kg}$, reduced brain inositol levels by $30 \%$ and increased inositol monophosphate levels 20-fold after 6 h (Allison et al. 1976, 1980) and 40-fold after $24 \mathrm{~h}$ (Sherman et al. 1985b). Chronic administra- 
tion of $\mathrm{Li}^{+}$has been reported to reduce brain inositol levels (Sherman et al. 1985b), but others have not replicated this critical finding (Jope and Williams 1994) (see below).

Various biological effects of $\mathrm{Li}^{+}$can be reversed by addition of myo-inositol in vitro (Kofman and Belmaker 1993). To ascertain if $\mathrm{Li}^{+\prime}$ s inhibition of inositol monophosphatase is relevant to its therapeutic effects in patients with affective disorders, it is critical to demonstrate that behavioral effects of $\mathrm{Li}^{+}$are also reversed by myo-inositol. Because myo-inositol does not easily penetrate the blood-brain barrier when injected systemically (Spector and Lorenzo 1975), it is preferable to inject myo-inositol directly into the brain. ICV myoinositol was found to reverse inhibition of rearing in rats induced by an acute injection of $\mathrm{Li}^{+}$(Kofman and Belmaker 1993).

\section{INOSITOL REVERSES Li-PILOCARPINE SEIZURES}

One of the most robust behavioral effects of $\mathrm{Li}^{+}$is that normally subconvulsant doses of muscarinic agonists will induce limbic seizures in rats pretreated with lithium (Honchar et al. 1983). Induction of $\mathrm{Li}^{+}$-pilocarpine seizures is concomitant with a reduction in cortical myo-inositol levels and an elevation of inositol monophosphate, which is about 10 -fold greater than the effects elicited by either $\mathrm{Li}^{+}$or pilocarpine alone (Sherman et al. 1985a, 1986). Tricklebank et al. (1991) reported that ICV injections of myo-inositol prolonged the latency to seizures elicited by ICV or systemic $\mathrm{Li}^{+}$in mice. We found similar results in rats (Kofman et al. 1993).

\section{Surgery and Injection}

Twenty-eight male Sprague-Dawley rats were implanted with guide cannulae in the lateral ventricle using standard stereotaxic procedures under pentobarbital anesthesia. Coordinates for the cannula placement were $0.8 \mathrm{~mm}$ posterior to bregma, $1.4 \mathrm{~mm}$ lateral to midline, and $5.0 \mathrm{~mm}$ below skull surface. Rats were randomly divided into three groups and injected ICV with myo-inositol or artificial cerebrospinal fluid (CSF) via an injection cannula attached with polyethelene tubing to a $100-\mu l$ Koehln microsyringe. As a control, the inositol stereoisomer, L-chiro-inositol was injected in a third group of rats. Myo- and L-chiro-inositol were injected in a dose of $10 \mathrm{mg} / 40 \mathrm{ul}$, and CSF was injected in a volume of $40 \mathrm{ul}$. Injections were made manually over a period of 2 minutes, and the injection cannula was left in place for $1 \mathrm{~min}$ before being replaced by the stylet. Then rats were injected with $\mathrm{LiCl}, 3 \mathrm{meq} / \mathrm{kg}$ in a volume of $15 \mathrm{cc} / \mathrm{kg}$ IP. Twenty-four hours later, they were reinjected ICV with the same drug they had received the previous day, and $30 \mathrm{~min}$ later, they were injected with pilocarpine, $30 \mathrm{mg} / \mathrm{kg}$, sc, or $20 \mathrm{mg} / \mathrm{kg}$ sc.

\section{Behavioral Observations}

The animals were rated for signs of seizure according to a modified version of the scale used by Patel et al. (1988) once every 5 minutes for 75 minutes. The scoring was as follows: $0=$ no response; $1=$ gustatory movements and/or fictive scratching; $2=$ tremor; $3=$ head bobbing; $4=$ forelimb clonus; 5 = rearing, clonus, and falling. In addition, the latency to attain forelimb clonus (score 4) was recorded for each rat. The observer was blind to the treatment condition.

Brains were removed and frozen for biochemical analysis and confirmation of cannula site. The frozen brains were cut at the cannula site, and those subjects that did not have cannulae in the lateral ventricle were excluded from behavioral and biochemical analysis.

\section{Results}

Latency to clonus was significantly prolonged by myoinositol (41.2 $\mathrm{min}$ ) as compared to artificial CSF (19.5 $\min )$ or L-chiro-inositol (16.9 $\mathrm{min}), \mathrm{F}=10.48, p=$ $.00074)$, in rats treated with lithium and pilocarpine 30 $\mathrm{mg} / \mathrm{kg}$. Post-hoc Scheffe tests indicated that there was a significant difference between myo-inositol and L-chiroinositol $(p<.002)$ and between myo-inositol and artificial CSF $(p=.005)$.

The seizure score was analyzed by Kruskal-Wallis test at each time point. There was a significant difference between the three groups at 20, and 30 to $45 \mathrm{~min}$ (Figure 1A) for $30 \mathrm{mg} / \mathrm{kg}$ pilocarpine.

The latency to exhibit clonus in rats treated with $\mathrm{Li}^{+}$ and pilocarpine, $20 \mathrm{mg} / \mathrm{kg}(\mathrm{F}=28.35, p<.00001)$ significantly increased with myo-inositol. Post-hoc Scheffe tests indicated that this difference was significant when myo-inositol was compared to vehicle $(p<.00002)$ and to L-chiro-inositol $(p<.00002)$; using Kruskal-Wallis, there was a significant effect of myo-inositol at 25 to 50 min and 60 to 75 min (Figure 1B).

Eight of 16 rats treated with myo-inositol did not attain seizure scores of 4 (clonus) or higher during the 75min observation period (and until sacrifice); whereas, only one of the 14 vehicle-treated rats did not exhibit clonus. All the rats treated with L-chiro-inositol had clonic seizures. A chi-square test for the number of animals that did not reach stage 4 indicated a significant difference between myo-inositol and vehicle groups $(p<$ .01 ) and between myo-inositol and L-chiro-inositol groups $(p<.004)$. There was no significant difference between the vehicle and L-chiro-inositol groups (Table 1). There was no effect of myo-inositol in $\mathrm{Li}^{+}$-free rats injected with pilocarpine, $200 \mathrm{mg} / \mathrm{kg}$ (data not shown). 

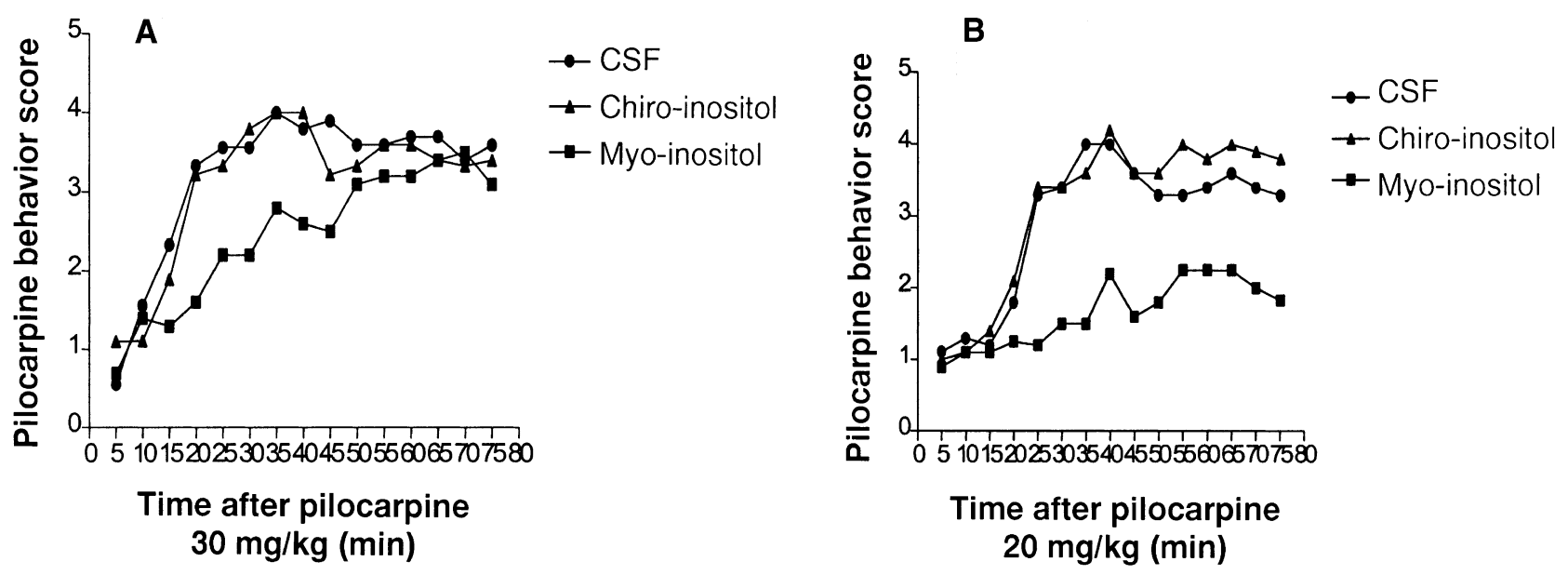

Figure 1. Score representing the intensity of pilocarpine-induced behaviors (ordinate) as described in the text. Abscissa represents the time in minutes following the injection of pilocarpine. (A) $30 \mathrm{mg} / \mathrm{kg}$ pilocarpine. Kruskal-Wallis tests indicated a significant effect of myo-inositol at $20 \mathrm{~min}(\mathrm{H}=9.55, p<.01), 30 \mathrm{~min}(\mathrm{H}=12.42, p<.005), 35 \mathrm{~min}(\mathrm{H}=8.06, p<.02), 40 \mathrm{~min}$ $(\mathrm{H}=12.69, p<.002)$, and $45 \mathrm{~min}(\mathrm{H}=12.97, p<.002)$. (B) $20 \mathrm{mg} / \mathrm{kg}$ pilocarpine. Kruskal-Wallis tests showed a significant effect of myo-inositol at $25 \mathrm{~min}(\mathrm{H}=14.28, p<.001), 30 \mathrm{~min}(\mathrm{H}=13.97, p<.001), 35 \mathrm{~min}(\mathrm{H}=16.31, p<.0005), 40 \mathrm{~min}(\mathrm{H}=$ $9.6, p<.01), 45 \min (\mathrm{H}=14.48, p<.001), 50 \mathrm{~min}(\mathrm{H}=9.51, p<.01)$ and $55 \min (\mathrm{H}=7.25, p<.05), 65 \mathrm{~min}(\mathrm{H}=7.68, p<.05)$, $70 \min (\mathrm{H}=8.69, p<.05)$ and $75 \min (\mathrm{H}=9.38, p<.01)$.

These results suggest that myo-inositol depletion is critical to the development of $\mathrm{Li}^{+}$-pilocarpine seizures. The ICV injections of myo-inositol elevated cortical myo-inositol levels and simultaneously attenuated and prevented $\mathrm{Li}^{+}$-pilocarpine seizures. The fact that seizures induced by a high dose of pilocarpine alone were not attenuated by myo-inositol suggests that the myoinositol reversal is specific to the $\mathrm{Li}^{+}$effect.

\section{THE EPI-INOSITOL PROBLEM}

However, Williams and Jope (1995) found that the stereoisomer epi-inositol, which was not incorporated into PI, also prevents lithium-pilocarpine seizures. This unexpected effect of a stereoisomer, which, in contrast to myo-inositol, did not reverse either the teratogenic effect of lithium in xenopus oocytes (Busa and Gimlich 1989) or the suppression of neuronal firing of suprachiasmatic nucleus cells by lithium in vitro (Mason and Biello 1992), suggested that the mechanism of the reversal of behavioral effects of lithium by myo-inositol may

Table 1. Number of Rats Exhibiting Clonic Seizures (Score 4) in Rats Treated with $3 \mathrm{meq} / \mathrm{kg} \mathrm{Li}^{+} \mathrm{IP}$ and $20 \mathrm{mg} / \mathrm{kg}$ pilocarpine SC $24 \mathrm{~h}$ Later

\begin{tabular}{lccc}
\hline ICV Treatment & No Seizure & Seizure & Total \\
\hline Artificial CSF & 1 & 13 & 14 \\
L-chiro-Inositol & 0 & 12 & 12 \\
Myo-Inositol & 8 & 8 & 16 \\
\hline
\end{tabular}

Chi-square for myo-inositol vs. vehicle $=6.53, p<.01$.

Chi-square for myo-inositol vs. chiro-inositol $=8.40, p<.004$. be unrelated to the metabolism of PI-derived second messengers. Moreover, Williams and Jope (1995) reported that myo-inositol delayed, but did not prevent seizures induced by administration of pilocarpine to rats treated with chronic dietary lithium, raising the possibility that myo-inositol may not be relevant to chronic behavioral effects of lithium.

Following the report by Williams and Jope (1995), we conducted a series of studies in an attempt to define the conditions under which the epi- and myo-inositol isomers reversed lithium-pilocarpine seizures (Patishi et al. 1996b). Three questions were raised: (1) Is epiinositol effective following acute and chronic lithium treatment? (2) Can a low dose of myo-inositol, combined with an inactive stereoisomer of inositol, effectively attenuate lithium-pilocarpine seizures? Because epi-inositol could conceivably be converted to myoinositol and may contain up to $10 \%$ of the active isomer (WR Sherman, personal communication), it was hypothesized that a low dose of myo-inositol, coadministered with a biologically inactive isomer, may be equally effective in reducing the effects of lithium. Myo-inositol is sequestered in various pools, and it has been estimated that only about $15 \%$ of cellular myoinositol is involved in second messenger synthesis (Fain and Berridge 1979; Sherman 1991). Conceivably, under conditions of lithium-induced inositol depletion, the "false" inositol, might stimulate the release of myoinositol from a hitherto "inactive" pool. (3) Is myo-inositol effective following chronic lithium, as has been previously reported for acute lithium treatment?

We (Patishi et al. 1996b) were able to replicate the results of Williams and Jope (1995), showing that epi- 
inositol is also effective in attenuating lithium-pilocarpine seizures. Both myo-inositol and epi-inositol, also effectively prevented lithium-pilocarpine seizures following chronic lithium (Table 2).

Epi-inositol ICV attenuated seizures after both acute and chronic lithium. After acute lithium, 4/6 control rats, but only $1 / 7$ rats treated with myo-inositol, and $0 / 7$ rats treated with epi-inositol had seizures. Following chronic lithium, epi-inositol also reduced the number of rats showing clonus, preventing seizures in 3 of 8 rats $\left(c^{2}=3.69, p=.055\right)$. All of the control rats had seizures. The latency to onset of clonus was significantly longer in epi-inositol-treated rats $(59.2 \pm 8.04 \mathrm{~min}$, mean $\pm \mathrm{SD})$ than in control rats $(27 \pm 11.67 \mathrm{~min})(t=5.38, p<$ .0005). The serum lithium levels were $1.24 \pm 0.5 \mathrm{mmol} / 1$ for the epi-inositol group and $1.22 \pm 0.4 \mathrm{mmol} / 1$ for the control group.

The inactive steroisomer L-chiro-inositol, adulterated with a low dose of myo-inositol, did not affect lithium-pilocarpine seizures. Two of 12 rats treated with 9 $\mathrm{mg}$ l-chiro-inositol and $1 \mathrm{mg}$ myo-inositol and 2/10 rats treated with vehicle did not have behavioral seizures. This difference was not statistically significant $\left(c^{2}=\right.$ $0.04)$. The latency to the onset of seizures was $33 \pm 15.53$ min (mean $\pm \mathrm{SD}$ ) in the control rats and $42.1 \pm 12.71$ $\mathrm{min}$ in the inositol-treated rats.

ICV myo-inositol prevented lithium-pilocarpine seizures following chronic dietary lithium. After chronic lithium treatment, only two of seven rats pretreated with ICV myo-inositol had lithium-pilocarpine seizures; whereas, all seven of the vehicle-treated rats showed seizures at a mean latency of $22.14 \pm 8.49$ (mean $\pm \mathrm{SD}$ ) minutes. The reduction in the incidence of clonus by myo-inositol was significant $\left(c^{2}=7.78, p<.01\right)$.

The finding that epi-inositol effectively blocked the onset of seizures in rats treated with acute or chornic lithium, followed by $20 \mathrm{mg} / \mathrm{kg}$ pilocarpine replicates the findings reported by Williams and Jope (1995). However, in contrast to their findings, we (Patishi et al. 1996b) found that both myo- and epi-inositol isomers were effective when rats were treated with chronic lithium using a lower dose of pilocarpine and a longer interval between the administration of myo-inositol and pilocarpine than they used. It is likely that the absence of blockade of chronic lithium-pilocarpine seizures by myo-inositol reported by Williams and Jope, can be attributed to differences in the dose of pilocarpine (30 vs. $20 \mathrm{mg} / \mathrm{kg}$ ) and the interval between administration of ICV inositol and pilocarpine (30 min vs. one h). Williams and Jope found an increased latency to onset of seizures in the myo-inositol-treated group following chronic lithium, similar to that reported by our group using a higher dose $(30 \mathrm{mg} / \mathrm{kg})$ of pilocarpine and acute lithium (Kofman et al. 1993).

Although these data support the relevance of inositol depletion to chronic lithium treatment, it was unclear why the epi-inositol stereoisomer would be as effective as myo-inositol. Epi-inositol does not seem to be a substrate for phosphatidylinositol synthase (Benjamins and Agranoff 1969) nor, unlike myo-inositol, does it reverse teratogenic effects of lithium (Busa and Gimlich 1989) or lithium-induced suppression of suprachiasmatic nucleus cell firing in vitro (Mason and Biello 1992). It was, therefore, critical to re-examine the claim of Williams and Jope (1995) that epi-inositol is biochemically inactive in the PI cycle. To avoid the confounding effects of exogenous inositols on the specific activity of radiolabeled myo-inositol, the turnover of the PI cycle was determined by measuring levels of tritiated cytidine monophosphorylphosphatidate $\left(\left[{ }^{3} \mathrm{H}\right] \mathrm{CMP}-\mathrm{PA}\right)$ in intact Chinese hamster ovary cells or cross-chopped slices of rat cerebral cortex (Richards and Belmaker 1996). These tissues were incubated in physiological buffer containing $\left[{ }^{3} \mathrm{H}\right]$ cytidine in the absence or presence of increasing concentrations of myo-, epi-, L-chiro-, and scyllo-inositol for $60 \mathrm{~min}$ at $37^{\circ} \mathrm{C}$. Carbachol and lithium (1 and 10 $\mathrm{mM}$ final concentrations, respectively) were then added, and the incubation continued for $30 \mathrm{~min}$. Incor-

Table 2. Summary of the Effect of ICV myo-Inositol and epi-Inositol Following Various Regimens of Lithium Administration and $20 \mathrm{mg} / \mathrm{kg}$ Pilocarpine

\begin{tabular}{lccc}
\hline Lithium Regimen & ICV Treatment & $\begin{array}{c}\text { No. Animals } \\
\text { with Clonus }\end{array}$ & $\begin{array}{c}\text { Mean + SD Latency to } \\
\text { Onset of Clonus (min) }\end{array}$ \\
\hline Acute 3 meq/kg & Vehicle & $4 / 6$ & $\mathrm{NA}$ \\
& $\begin{array}{c}\text { epi-inositol } \\
\text { myo-inositol }\end{array}$ & $0 / 7$ & \\
Chronic dietary-21 days & Vehicle & $1 / 7$ & $27 \pm 11.67$ \\
& epi-inositol & $8 / 8$ & $59.2 \pm 8.04$ \\
Acute 3 meq/kg & Vehicle & $5 / 8$ & $33 \pm 15.53$ \\
& $90 \%$ L-chiro- & $10 / 12$ & $42.1 \pm 12.71$ \\
Chronic dietary-21 days & $10 \%$ myo-inositol & & $22.14+8.49$ \\
& Vehicle & $7 / 7$ & $\mathrm{NA}$ \\
\hline
\end{tabular}

NA-Latencies are not shown in cases where the number of rats showing seizures is small. 
poration of radioactivity into cell membranes was quantified by scintillation spectrometry. In $\mathrm{CHO}$ cells, the accumulation of $\left[{ }^{3} \mathrm{H}\right] \mathrm{CMP}-\mathrm{PA}$ was $60 \pm 10$ times basal $(n=$ 13) in the presence of carbachol plus lithium. Neither scyllo-inositol (up to $10 \mathrm{mM}$ ) nor L-chiro-inositol (up to $30 \mathrm{mM}$ ) had an effect on the stimulated formation of $\left[{ }^{3} \mathrm{H}\right] \mathrm{CMP}-\mathrm{PA}$ (Figure 2); whereas, $25 \mathrm{mM}$ scyllo-inositol slightly inhibited the response $(<20 \%)$. In contrast, both myo-inositol and epi-inositol concentration-dependently inhibited the accumulation of $\left[{ }^{3} \mathrm{H}\right] \mathrm{CMP}-\mathrm{PA}$ induced by carbachol plus lithium (Figure 2). Full inhibition was attained with $10 \mathrm{mM}$ myo-inositol; whereas, epi-inositol at $30 \mathrm{mM}$ inhibited response by $83 \pm 4 \%(n=6)$. Myoinositol was slightly but significantly $(p<.001$, unpaired $t$-test) more potent than epi-inositol: $\mathrm{EC}_{50}$ values were $1.9 \pm 0.2$, and $6.1 \pm 0.6 \mathrm{mM}$, respectively $(n=6$ for each). Although a smaller stimulation of $\left[{ }^{3} \mathrm{H}\right] \mathrm{CMP}-$ PA by carbachol plus lithium was found in rat cerebral cortex cross-chopped slices $(9.8 \pm 1.2$ times basal, $n=$ $3)$, the same order of activity was observed for the four inositol isomers in the two tissues (Richards and Belmaker 1996). Thus, there is a precise correlation between the effects of the four inositol isomers on PI turnover, as measured by their effects on the accumulation of $\left[{ }^{3} \mathrm{H}\right] \mathrm{CMP}-\mathrm{PA}$ in two tissues, with their effects on lithium-pilocarpine-induced seizures. Both in vitro and in

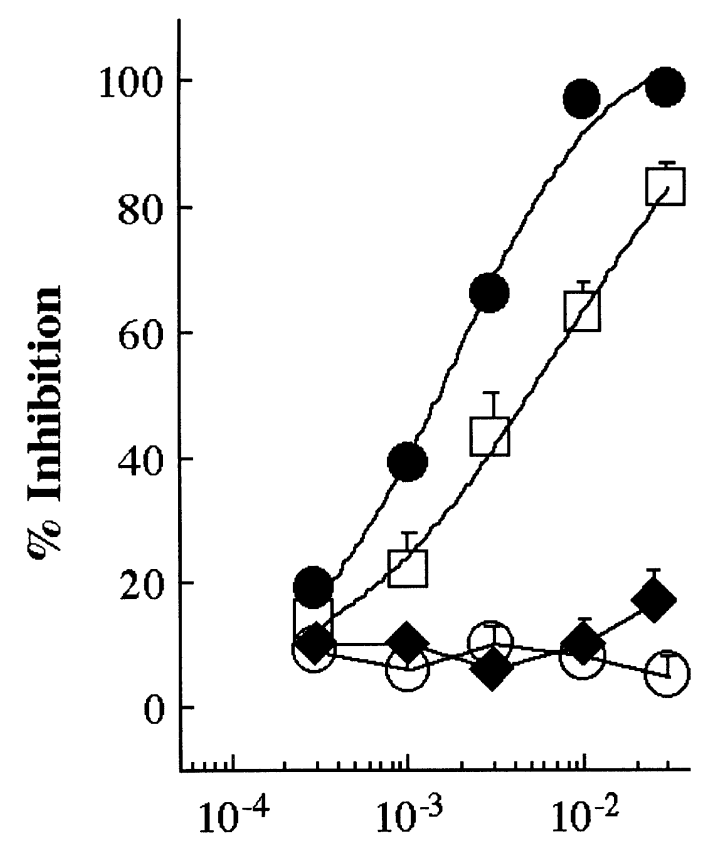

\section{Molar Concentration}

Figure 2. Inhibition of stimulated $\left[{ }^{3} \mathrm{H}\right] \mathrm{CMP}-\mathrm{PA}$ formation in CHOm3 cells by myo-inositol ( $(\mathbf{)}$, epi-inositol ( $\square)$, scylloinositol $(\diamond)(n=6$ for each) and L-chiro-inositol $(\bigcirc, n=3)$. Values are means \pm SEM for $(n)$ experiments. (From Richards and Belmaker 1996). vivo, L-chiro- and scyllo-inositol had little or no effect; whereas, epi-inositol was less potent but almost as effective as myo-inositol. The perfect rank order of activity of these four inositol isomers in biochemical and behavioral tests strongly suggest a common basis of action.

\section{ANATOMICAL SPECIFICITY OF INOSITOL DEPLETION BY LITHIUM}

Although attractive and seminal, the "inositol depletion hypothesis" has been questioned on the grounds that, even with toxic doses of lithium, the brain's depletion of inositol is only small and might be restricted to acute treatment. Furthermore, although in vitro and ex vivo experiments indeed showed an attenuation of agoniststimulated inositol phosphate formation in brain slices of lithium-treated rats, these effects were apparently caused by an exaggerated depletion of inositol in the slice system and were not observed in other species, in which the supply of inositol is not as readily compromised (Jope and Williams 1994). It has been argued, however, that a lithium-induced depletion of inositol might be limited to selected brain areas or even cells that might be particularly vulnerable to this effect because of restricted inositol supply and/or increased activity of the inositol phospholipid second messenger system (Nahorski et al. 1991).

We (Lubrich et al. 1997) have, therefore, measured the effect of both acute and chronic treatment with lithium on the inositol content in various areas of rat brain. The results indicate that after chronic treatment, a lithium-induced decrease in inositol is significantly evident in the hypothalamus (Lubrich et al. 1997).

Rats were fed chow containing $0.2 \%$ Li chloride for 21 days or regular feed. Separate bottles of water and $0.9 \% \mathrm{NaCl}$ solution were provided ad libitum for both groups of animals. After 21 days, animals were sacrificed by decapitation, the fresh brains were dissected into five regions, Li levels were measured in carotid blood and were found to be $0.79 \pm 0.16 \mathrm{mM}$. Samples were stored at $-70^{\circ} \mathrm{C}$ until assay by high-performance liquid chromatography (HPLC) analysis blind to the treatment of each sample.

All reagents were purchased from Merck (Darmstadt) with the exception of glucose oxidase and pyridine from Sigma (Munich). Pyridine was kept dry by storing over a molecular sieve $0.4 \mathrm{~nm}$ (Merck, Darmstadt). Solvents for the mobile phase and chloroform for dissolving the derivates were all HPLC grade. All other chemicals were analytical grade. A Waters HPLC system of Waters 501 pump and a Waters 486 UV detector set at $254 \mathrm{~nm}$ were used for all HPLC separations. As column, a $10-\mu$ porasil column $(4.6 \times 300 \mathrm{~mm})(\mathrm{Grom} /$ Herrenberg-Kayh) was used. The frozen tissue was 
thawed and roughly homogenized with a spatula, while kept on ice. To an aliquot of 5 to $15 \mathrm{mg}$ of each sample $500 \mu$ l of deionized water was added, then vortexed for $10 \mathrm{~s}$. The samples were deproteinated by heating to $95^{\circ} \mathrm{C}$ for $5 \mathrm{~min}$. After vortexing once more, the homogenates were centrifuged at $13,000 \mathrm{~g}$ for $30 \mathrm{~min}$ at $5^{\circ} \mathrm{C}$. The entire supernatant was transferred to $2-\mathrm{ml}$ plastic tubes with 20 units glucose oxidase. The tubes were then incubated for $40 \mathrm{~min}$ at $37^{\circ} \mathrm{C}$ in a shaking water bath. Aliquots of $50 \mu \mathrm{l}$ of each sample were transferred to glass tubes (Assistent/Sondheim-Roehn) containing $0.2 \mu \mathrm{l}$ epi-inositol as internal standard. The probes were evaporated in a vacuum centrifuge (Speed vac 200, Bachofer / Reutlingen), followed by addition of $200 \mu \mathrm{l}$ of a freshly prepared solution of $20 \%(\mathrm{w} / \mathrm{v})$ p-nitrobenzoyl chloride in pyridine to each sample. After mixing, samples were incubated for $90 \mathrm{~min}$ at $60^{\circ} \mathrm{C}$. The reaction was stopped by adding a few drops of deionized water until a solid pellet formed. Immediately, $2 \mathrm{ml}$ of chloroform were added, and the pellet was dissolved by vortexing vigorously. Six extractions were performed with twice 2 $\mathrm{ml}$ deionized water, twice $2 \mathrm{ml} 5 \% \mathrm{NaHCO} 3(\mathrm{w} / \mathrm{v})$, and twice $3 \mathrm{ml} 1 \mathrm{~N} \mathrm{HCl}$. Following each extraction, the samples were centrifuged for $1 \mathrm{~min}$ to separate the phases, and the aqueous phase was eliminated. Twenty $\mu$ l of the organic phase were injected into a $10-\mu$ porasil column, using hexane-chloroform-acetonitrile (10:3:2) and water $0.1 \%$ as mobile phase. The flow rate was $1.5 \mathrm{ml} /$ min. The integrator was calibrated using pure standards at several concentrations between 0 and $1.5 \mu \mathrm{g}$ for myo-inositol and 0 and $0.5 \mu \mathrm{g}$ for epi-inositol. UV detection was at $254 \mathrm{~nm}$. Retention times were about 12 min for myo-inositol and 14 min for epi-inositol, respectively. Each sample was analyzed in duplicate.

After chronic dietary administration of $\mathrm{LiCl}$, a significant reduction of inositol was found only in the hypothalamus $(p<.01)$ whereas no effect was found in the other brain areas (Table 3). This reduction was significant even after Bonferroni correction for multiple testing (five areas). No (Sherman et al. 1981; Hirvonen and Savolainen 1991; Whitworth and Kendall 1989), or only minute (Sherman et al. 1985a), reductions of the inositol content in various rat brain areas have been found after chronic treatment with lithium given either as daily injection [3.5 or $2.5 \mathrm{mEq} / \mathrm{kg}$, (Sherman et al. 1981; Hirvonen and Savolainen)] or in the diet (Sherman et al. 1985; Withworth and Kendall 1989), and dietary lithium was even reported to increase cortical inositol by $30 \%$ (Withworth and Kendall 1989). In agreement with most reports, we found no alteration of inositol after chronic lithium treatment in the brain areas examined, with the exception of the hypothalamus. This region has, to our knowledge, never been previously examined after chronic treatment, but a $26 \%$ reduction of inositol was found 6 hours after acute injection of $10 \mathrm{mEq} / \mathrm{kg}$ lithium (Sherman et al. 1986).
The effect observed in the hypothalamus is interesting, because this region has been implicated in the neurobiology of affective disorders. Previous work from our groups has shown that the hypothalamus, the brain region with the highest basal inositol content (Table 3), accumulates inositol given intraperitoneally more efficiently than other brain regions, particularly the cortex, the region with the lowest basal inositol content (Patishi et al. 1996c).

\section{INOSITOL IN POSTMORTEM BRAIN}

Lithium reduces brain inositol levels (Allison and Stewart 1971), and considerable research has focused on the role of inositol in the mechanism of action of Li (Kofman and Belmaker 1993). Somewhat paradoxically, Barkai et al. (1978) reported that inositol is reduced in CSF in both bipolar and unipolar depressed patients. Levine et al. (1993) gave inositol to 11 unipolar-resistant depressed patients, with dramatic results in seven of the 11. Levine et al. (1995) then performed a controlled double-blind study of 28 depressed patients with $12 \mathrm{gm}$ of inositol or placebo for 4 weeks. Inositol treatment reduced Hamilton Depression Scale Scores (HDS) significantly more than placebo. We (Shimon et al. 1997) were able to measure inositol and inositol monophosphatase, the enzyme that forms inositol in brain, in postmortem brain specimens from patients with bipolar affective disorder, in suicides, and in normal controls.

Brain specimens in the National Institute of Mental Health (NIMH) brain collection were obtained at autopsy from the Washington, DC Medical Examiner's office. Blood and urine samples were collected at the same time for toxicological analysis and for neuroleptic level determination. None of the subjects had measurable serum levels at the time of death. All brains were screened by a neuropathologist for confounding neurological conditions (none were found in the specimens used in this study). Psychiatric diagnosis was determined by independent review of medical records by at least two psychiatrists. After collection from autopsy, the brain tissue was dissected into $1-\mathrm{cm}$ coronal slabs,

Table 3. Effect of Chronic Lithium on Brain Inositol Levels (mmol/kg wet weight)

\begin{tabular}{lll}
\hline & Control & Li-Treated \\
\hline Hypothalamus & $4.37 \pm 1.37$ & $3.46 \pm 0.96^{*}$ \\
Cortex & $2.31 \pm 0.66$ & $2.23 \pm 0.86$ \\
Cerebellum & $3.08 \pm 1.1$ & $2.79 \pm 0.8$ \\
Caudate & $2.65 \pm 0.89$ & $2.66 \pm 0.79$ \\
Hippocampus & $3.12 \pm 1.01$ & $2.82 \pm 0.73$ \\
\hline
\end{tabular}

Effects of chronic (3 weeks) dietary treatment with lithium $(0.2 \% \mathrm{LiCl}$ $\mathrm{w} / \mathrm{w}$ ) on the level of inositol in five brain regions. Student's $t$-test was significant for hypothalamus $(p=.004)$. Chronic oral lithium lowers inositol by $27 \%$. 
which were individually frozen in isopentane cooled with dry ice $\left(-40^{\circ} \mathrm{C}\right)$. Tissue blocks were stored at $-70^{\circ} \mathrm{C}$ until dissection for this study. Postmortem interval (PMI) was defined as the time from death until removal of the brain into the frozen state. Lithium was measured in bipolar patient and suicide victim brains by flame emission spectroscopy and was undetectable in all, except for three bipolar patients with levels of $0.35,0.48$, and $0.23 \mathrm{mmol} / \mathrm{kg}$ wet weight.

Human brain free myo-inositol levels were analyzed as trimethylsilyl (TMS) derivatives by gas-liquid chromatography, as previously described by Allison et al. (1976), with minor modification. Samples of tissue (approximately $50 \mathrm{mg}$ ) were dissected from the various brain areas, weighed, extracted in $0.5 \mathrm{ml}$ of boiling water containing $400 \mu \mathrm{g}$ mannitol for $5 \mathrm{~min}$, the denatured

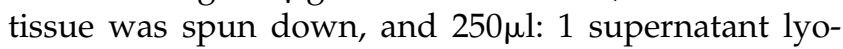
philized (3 h Speed Vac SC 110); silylation of the dried sample was carried out with $200 \mu 1: 1$ of a mixture of pyridine: bis(trimethylsilyl) trifluoroacetamide: chlorotrimethylsilan 10:2:1 (v/v/v) for $24 \mathrm{~h}$ at room temperature. $2 \mu \mathrm{l}$ : 1 aliquots were chromatographed on a 6 - $\mathrm{ft}$ column packed with $3 \%$ SE-30 on $80 / 100$ mesh gas chrome Q (Supelco), using a Carlo Erba SCU 600 gas chromatograph with a hydrogen flame ionization detector. The oven temperature was isothermal at $220^{\circ} \mathrm{C}$, and the carrier gas was nitrogen with a flow of $120 \mathrm{ml} /$ $\mathrm{min}$. The TMS derivatives of mannitol and myo-inositol had retention times of 7 and $11 \mathrm{~min}$, respectively. Under these conditions, quantitation was performed with the use of TMS derivatives of standard myo-inositol under the same conditions and with mannitol as an internal standard. Standard curves were run daily, and lin- earity was verified at the beginning and periodically during the processing of the samples.

Enzyme activity was measured (Hallcher and Sherman 1980) in brain homogenates obtained by the addition of $2.0 \mathrm{ml}$ of homogenization buffer $(50 \mathrm{mM}$ Tris- $\mathrm{HCl}$ $\mathrm{pH} 8.5,150 \mathrm{mM} \mathrm{KCl}, 0.5 \mathrm{mM}$ EDTA and $0.1 \mathrm{mM}$ EGTA) to $0.1 \mathrm{~g}$ of tissue. Brain homogenization was carried out in a cell disrupter followed by $15 \mathrm{~min}$ centrifugation at $7,500 \mathrm{~g}$ and $4^{\circ} \mathrm{C}$. The reaction mixture contained in a final volume of $210 \mu \mathrm{l}: 1,0.7 \mathrm{mM}$ inositol-1-phosphate, 50 $\mathrm{mM}$ Tris- $\mathrm{HCl} \mathrm{pH} 7.8,250 \mathrm{mM} \mathrm{KCl}, 3 \mathrm{mM} \mathrm{MgCl}$ and

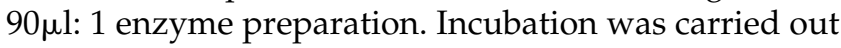
for 1 hour at $37^{\circ} \mathrm{C}$ and then $10 \mu \mathrm{l}$ : 1 of $100 \%$ solution tricholoroacetic acid (TCA) were added to stop the reaction. The mixture was centrifuged for $15 \mathrm{~min}$ at $7,500 \mathrm{~g}$ and $4^{\circ} \mathrm{C}$. Inorganic phosphate in the supernatant was determined spectrophotometrically (Taussky et al. 1953). To distinguish inositol monophosphatase activity from nonspecific phosphatases, we use the fact that inositol monophosphatase is inhibited by Li. The reaction was carried out in the absence and in the presence of 30 $\mathrm{mM} \mathrm{Li}$, each tube in triplicate. The enzyme activity was calculated as the difference between the values in the presence and in the absence of Li. Enzyme activity is calculated per mg protein, assayed according to Lowry et al. (1951).

All samples were assayed at least twice (of the triplicate tubes), and the results presented are the average of the replicates. Assays were performed in a balanced design so that each run included samples from each clinical group and controls and all available brain areas.

To evaluate possible effects of postmortem decay on brain inositol and inositol monophosphatase, rats were

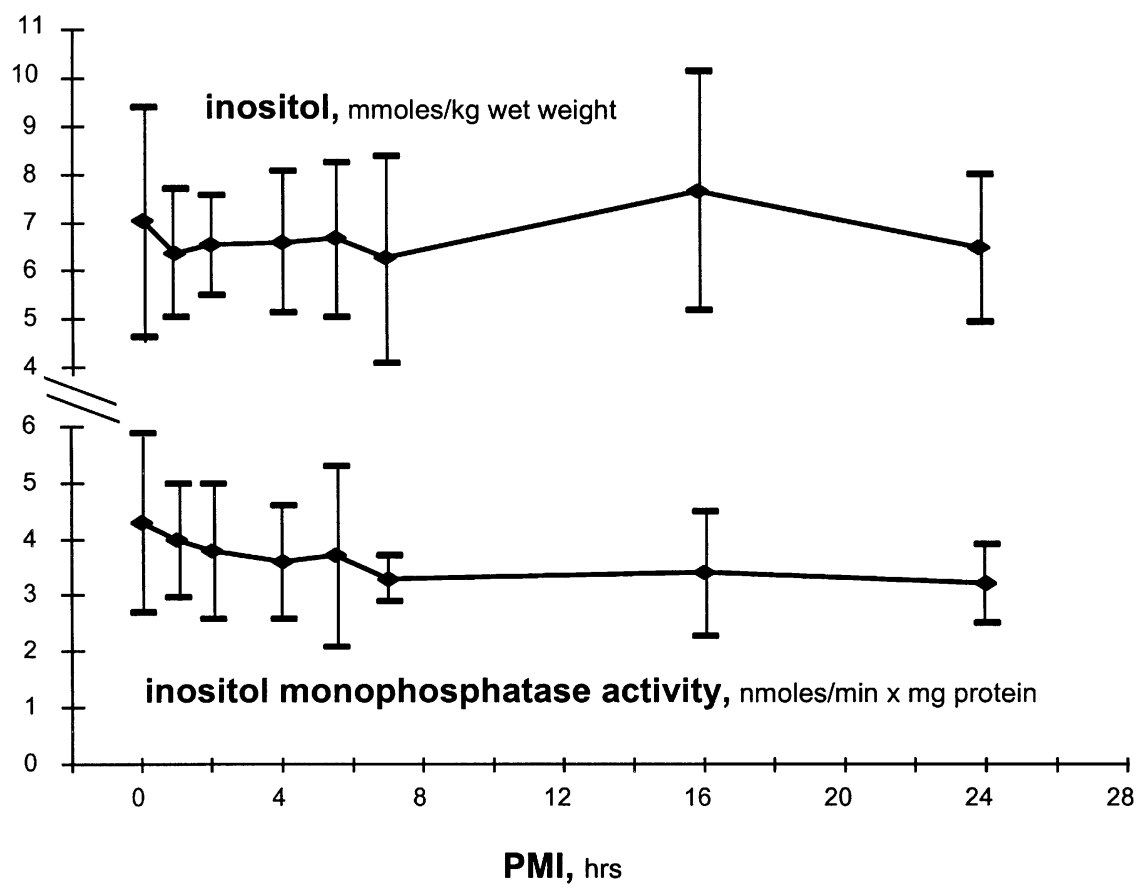

Figure 3. The effect of postmortem interval (PMI) on rat brain inositol monophosphatase activity and inositol levels ( \pm SD, $N=7-8$ at each time point). 
killed by decapitation, and the heads were left out at room temperature for $0,1,2,4,6,7,16$, or $24 \mathrm{hrs}$. After the specified times, the brains were removed from the skulls and frozen at $-70^{\circ} \mathrm{C}$, until assay as above for inositol and inositol monophosphatase. All assays were performed in a balanced design so that each run included one sample from each time point.

Figure 3 shows inositol levels and inositol monophosphatase levels up to $24 \mathrm{~h}$ after decapitation in rat brain. There was no significant effect of PMI up to $24 \mathrm{~h}$ on rat brain inositol or inositol monophosphatase activity.

Table 4 contains the demographic characteristics of the sample. Table 5 demonstrates the inositol results. Analysis of variance (ANOVA) shows a significant difference between the groups for frontal cortex $(\mathrm{F}=3.83$,

Table 4. Demographic Data

\begin{tabular}{|c|c|c|c|}
\hline & Bipolars & Suicide & Normal \\
\hline \multicolumn{4}{|l|}{ Run 1} \\
\hline Age $^{a}$ & 47 & 86 & 58 \\
\hline Sex & $\mathrm{F}$ & $\mathrm{F}$ & $\mathrm{F}$ \\
\hline $\mathrm{PMI}^{b}$ & 16.5 & 22.0 & 29.75 \\
\hline \multicolumn{4}{|l|}{ Run 2} \\
\hline Age & 49 & 65 & 68 \\
\hline Sex & $\mathrm{F}$ & $\mathrm{M}$ & $\mathrm{M}$ \\
\hline PMI & 28.0 & 19.75 & 19.75 \\
\hline \multicolumn{4}{|l|}{ Run 3} \\
\hline Age & 36 & 34 & 84 \\
\hline Sex & $\mathrm{F}$ & $\mathrm{F}$ & $\mathrm{M}$ \\
\hline PMI & 24 & 20.5 & 18.0 \\
\hline \multicolumn{4}{|l|}{ Run 4} \\
\hline Age & 51 & 55 & 47 \\
\hline Sex & $\mathrm{F}$ & $\mathrm{F}$ & $\mathrm{M}$ \\
\hline PMI & 17.25 & 24.0 & 24.0 \\
\hline \multicolumn{4}{|l|}{ Run 5} \\
\hline Age & 83 & 46 & 54 \\
\hline Sex & $\mathrm{F}$ & $\mathrm{F}$ & $\mathrm{M}$ \\
\hline PMI & 46.0 & 28.0 & 22.0 \\
\hline \multicolumn{4}{|l|}{ Run 6} \\
\hline Age & 64 & 29 & 39 \\
\hline Sex & $\mathrm{F}$ & $\mathrm{M}$ & $\mathrm{F}$ \\
\hline PMI & Unknown & 21.0 & 41.5 \\
\hline \multicolumn{4}{|l|}{ Run 7} \\
\hline Age & 50 & 52 & 46 \\
\hline Sex & M & $\mathrm{F}$ & $\mathrm{F}$ \\
\hline PMI & 21.25 & 15.0 & 22.5 \\
\hline \multicolumn{4}{|l|}{ Run 8} \\
\hline Age & 31 & 77 & 34 \\
\hline Sex & M & $\mathrm{M}$ & $\mathrm{M}$ \\
\hline PMI & Unknown & 26.5 & 14.0 \\
\hline \multicolumn{4}{|l|}{ Run 9} \\
\hline Age & & 41 & 47 \\
\hline Sex & & $\mathrm{M}$ & $\mathrm{M}$ \\
\hline PMI & & 7.0 & 24.5 \\
\hline \multicolumn{4}{|l|}{ Run 10} \\
\hline Age & & 51 & 59 \\
\hline Sex & & $\mathrm{F}$ & $\mathrm{F}$ \\
\hline PMI & & 21.0 & 17.0 \\
\hline
\end{tabular}

${ }^{a}$ Age in years.

${ }^{b}$ PMI in hours. df $2 / 25, p=.035)$, but not for occipital cortex $(\mathrm{F}=1.8$, df $2 / 24, n s)$ or cerebellum ( $F=.03$, df $2 / 21, n s$ ). Posthoc $t$-test for frontal cortex shows suicides significantly lower than controls $(p=.01)$ and bipolars significantly less than controls $(p=.01)$. Omitting subjects with unknown PMI or PMI greater than 30 hours, ANOVA shows a significant difference for frontal cortex $(\mathrm{F}=$ 4.24 , df $2 / 21, p=.03$ ) and post-hoc $t$-test is significant for normals vs. bipolars $(p<.05)$, and normals vs. suicides $(p=.01)$.

Nonparametric analysis shows significant group difference with the Kruskall-Wallis ANOVA for frontal cortex $(2, \mathrm{H}=6.3, p=.04, N=28)$. Bipolars are lower than normals in frontal inositol with Kruskall-Wallis (1,

Table 5. Inositol Levels (mmole/ $\mathrm{kg}$ wet weight)

\begin{tabular}{|c|c|c|c|}
\hline \multicolumn{4}{|c|}{ Frontal } \\
\hline Run & Bipolar & Suicide & Normal \\
\hline A & 8.18 & 6.48 & 11.6 \\
\hline B & 7.05 & 6.35 & 10.4 \\
\hline $\mathrm{C}$ & 8.82 & 5.75 & 10.5 \\
\hline $\mathrm{D}$ & 4.90 & 6.02 & 7.02 \\
\hline $\mathrm{E}$ & 4.35 & 4.37 & 8.85 \\
\hline $\mathrm{F}$ & 2.27 & 5.23 & 6.55 \\
\hline G & 5.90 & 7.80 & 4.05 \\
\hline $\mathrm{H}$ & 5.75 & 5.40 & 11.4 \\
\hline I & - & 8.45 & 9.03 \\
\hline J & - & 12.1 & 8.05 \\
\hline$x \pm S D$ & $5.90 \pm 2.12$ & $6.74 \pm 2.21$ & $8.74 \pm 2.39$ \\
\hline \multicolumn{4}{|c|}{ Occipital } \\
\hline Run & Bipolar & Suicide & Normal \\
\hline A & 11.2 & 10.8 & 7.00 \\
\hline B & 7.24 & 5.55 & 6.35 \\
\hline $\mathrm{C}$ & 6.95 & 5.30 & 8.15 \\
\hline $\mathrm{D}$ & 5.55 & 5.77 & 9.25 \\
\hline $\mathrm{E}$ & - & 5.40 & 12.5 \\
\hline $\mathrm{F}$ & 1.77 & 7.65 & 6.55 \\
\hline G & 8.10 & 9.25 & 10.8 \\
\hline $\mathrm{H}$ & 6.05 & 3.15 & 16.5 \\
\hline I & - & 9.65 & 9.48 \\
\hline $\mathrm{J}$ & - & 6.66 & 4.20 \\
\hline$x \pm S D$ & $6.69 \pm 2.84$ & $6.91 \pm 2.37$ & $9.08 \pm 3.53$ \\
\hline \multicolumn{4}{|c|}{ Cerebellum } \\
\hline Run & Bipolar & Suicide & Normal \\
\hline $\mathrm{A}$ & 10.55 & 8.90 & 5.55 \\
\hline B & 5.0 & 4.35 & 4.45 \\
\hline $\mathrm{C}$ & - & 5.55 & 5.30 \\
\hline $\mathrm{D}$ & - & 5.57 & 8.30 \\
\hline $\mathrm{E}$ & - & 6.91 & 11.2 \\
\hline $\mathrm{F}$ & - & 5.55 & 13.80 \\
\hline G & 8.00 & 15.5 & 8.35 \\
\hline $\mathrm{H}$ & 5.35 & 5.00 & 7.15 \\
\hline $\mathrm{I}$ & - & 13.15 & 8.05 \\
\hline $\mathrm{J}$ & - & 6.85 & 4.75 \\
\hline$x \pm S D$ & $7.22 \pm 2.58$ & $7.72 \pm 3.73$ & $7.69 \pm 2.98$ \\
\hline
\end{tabular}


$N=18 ; \mathrm{H}=4.93 ; p=.026)$, and suicides are lower than normals in frontal inositol with Kruskall-Wallis $(1, N=$ $20 ; \mathrm{H}=3.86 ; p<.05)$. Omitting subjects with unknown PMI or PMI greater than 30 hours, Kruskall-Wallis ANOVA is even more significant $(2, N=24, \mathrm{H}=7.5$, $p=.02)$. Kruskall-Wallis for these data shows bipolar patients' frontal inositol lower than controls, $(\mathrm{H}, 1=$ 3.7; $N=14 ; p=.053$ ), and suicides' frontal inositol is lower than controls $(\mathrm{H}, 1=6.4 ; N=19 ; p=.011)$.

A parametric covariance analysis of frontal inositol levels with PMI as covariant was performed. ANOVA group difference after covariance was significant, $\mathrm{F}=$ 3.7 , df $2 / 22, p=.04)$. PMI correlated with frontal inositol $(r=-.39, N=26, p=.046)$. Excluding the two subjects with PMI greater than 30 hours, correlation of PMI and frontal inositol declined to $r=-.13$ (ns).

There was no significant correlation of age with frontal $(r=-.06)$, occipital $(r=-.16)$, or cerebellum $(r=$ $-.24)$ inositol levels. There was no significant difference in frontal cortex inositol between women $(6.7 \pm 2.7)$ and men $(7.9 \pm 1.9)$, in occipital cortex between women $(7.1 \pm 3.1)$ and men $(8.3 \pm 2.9)$, or in cerebellum between women $(7.4 \pm 2.3)$ and men $(8.4 \pm 3.7)$. In occipital cortex, PMI correlates with inositol, $r=-.27$ (ns) and in cerebellum, $r=-.23$ (ns).

Table 6 shows the inositol monophosphatase results. Inositol monophosphatase activity in these human brain cortex samples is less than one-third the activity in rat cortex (Patishi et al. 1996a), see Figure 3. Inositol monophosphatase activity does not correlate with PMI $(r=-.16$, frontal; $r=-.17$, occipital; and $r=-.13$, cerebellum). Inositol monophosphatase activity does not correlate with inositol levels (frontal $r=.11$, ns; occipital $r=-.11$, ns; cerebellum $r=-.15$, ns). Inositol monophosphatase activity correlates with age in frontal cortex $(r=.24, \mathrm{~ns})$ in occipital cortex $(r=.51, p=.01)$ and in cerebellum $(r=.51, p=.01)$. There was no difference in inositol monophosphatase activity between suicides, bipolar disorder, and normal control groups by ANOVA.

These data suggest that bipolar affective disorder and suicide victims may have a reduction in frontal cortical inositol levels as compared with controls, with a similar but statistically nonsignificant trend in occipital cortex. Cerebellum inositol shows no difference between the clinical groups. Interestingly, cerebellum also shows no increase in inositol-1-phosphate after Li treatment (Allison et al. 1976), suggesting that cerebellum inositol may be less involved in neuronal PI-linked signal transduction and more related to osmolyte function. A recent study found that exogenously administered inositol is taken up by cortex, hippocampus, and hypothalamus but not by cerebellum (Patishi et al. 1996c).

Inositol levels in the normal samples, about $9 \mathrm{mM}$, agree well with in vivo results by magnetic resonance spectroscopy (Gruetter et al. 1992). Dixon et al. (1992)
Table 6. Inositol Monophosphatase Activity $(\mathrm{nmol} / \mathrm{min} \times \mathrm{mg}$ protein)

\begin{tabular}{|c|c|c|c|}
\hline \multicolumn{4}{|c|}{ Frontal } \\
\hline Run & Bipolar & Suicide & Normal \\
\hline $\mathrm{A}$ & 1.899 & 1.298 & 1.547 \\
\hline B & 1.170 & 0.713 & 0.939 \\
\hline $\mathrm{C}$ & 0.467 & 1.599 & 2.038 \\
\hline $\mathrm{D}$ & 2.168 & 2.917 & 0.508 \\
\hline $\mathrm{E}$ & 0.648 & 0.723 & 1.275 \\
\hline $\mathrm{F}$ & 0.804 & 1.834 & 0.923 \\
\hline G & 0.818 & 1.631 & 0.388 \\
\hline $\mathrm{H}$ & 0.411 & 0.789 & 1.435 \\
\hline I & - & 0.632 & 1.034 \\
\hline $\mathrm{J}$ & - & 0.688 & 0.722 \\
\hline$x \pm S D$ & $1.047 \pm 0.655$ & $1.282 \pm 0.734$ & $1.081 \pm 0.503$ \\
\hline \multicolumn{4}{|c|}{ Occipital } \\
\hline Run & Bipolar & Suicide & Normal \\
\hline $\mathrm{A}$ & 3.655 & 1.888 & 1.753 \\
\hline $\mathrm{B}$ & 2.058 & 2.233 & 1.413 \\
\hline $\mathrm{C}$ & 0.315 & 2.184 & 3.961 \\
\hline $\mathrm{D}$ & 0.726 & 1.466 & 1.743 \\
\hline $\mathrm{E}$ & - & 0.844 & 1.316 \\
\hline $\mathrm{F}$ & 2.157 & 0.770 & 1.246 \\
\hline G & 0.802 & 0.854 & 1.164 \\
\hline $\mathrm{H}$ & 0.392 & 2.317 & 0.627 \\
\hline I & - & 1.052 & 0.713 \\
\hline $\mathrm{J}$ & - & 2.046 & 1.313 \\
\hline$x \pm S D$ & $1.458 \pm 1.222$ & $1.566 \pm 0.636$ & $1.524 \pm 0.931$ \\
\hline \multicolumn{4}{|c|}{ Cerebellum } \\
\hline Run & Bipolar & Suicide & Normal \\
\hline $\mathrm{A}$ & 1.902 & 1.837 & 1.446 \\
\hline B & 0.771 & 1.990 & 1.110 \\
\hline $\mathrm{C}$ & - & 0.297 & 1.280 \\
\hline $\mathrm{D}$ & - & 0.387 & 0.895 \\
\hline $\mathrm{E}$ & - & 0.542 & 0.364 \\
\hline $\mathrm{F}$ & - & 0.653 & 0.528 \\
\hline G & 0.469 & 0.281 & 0.275 \\
\hline $\mathrm{H}$ & 0.224 & 0.227 & 1.163 \\
\hline I & - & 0.370 & 0.285 \\
\hline $\mathrm{J}$ & - & 0.804 & 0.581 \\
\hline$x \pm S D$ & $0.841 \pm 0.741$ & $0.738 \pm 0.645$ & $0.792 \pm 0.439$ \\
\hline
\end{tabular}

reported that primate brain inositol levels are two times higher than those in the rat. The standard deviation of inositol levels in these postmortem samples is similar in controls and in suicides and bipolar patients, suggesting that postmortem degradation or agonal illness in a subgroup of patients are not critical factors in the reduced inositol levels. Moreover, the standard deviation is similar to that in freshly decapitated rat cortex (Agam et al. 1994; also see Figure 3).

There were no significant differences between clinical groups in inositol monophosphatase activity. Inositol monophosphatase has previously been reported to be elevated in red blood cells (RBC) of schizophrenic 
patients by 35\% (Zilberman-Kaufman et al. 1992). Inositol monophosphatase varies in RBC between individuals by a full order of magnitude (Agam and Livne 1989), and the variability in human brain between individuals is thus similar. Inositol monophosphatase activity increases with age (Patishi et al. 1996), as does the activity of monoamine oxidase (MAO), also a neurotransmitterrelated catabolic enzyme (Murphy et al. 1977). It is noteworthy that human brain inositol monophosphatase exhibits region differences as observed for rat brain inositol levels (Table 3). IMPase activity was lowest in cerebellum, highest in occiptal cortex, and medium in frontal cortex (Table 6).

Inositol levels and inositol monophosphatase activity do not clearly decline in the first $24 \mathrm{~h}$ postmortem, either in the rat experiment or in the human brain covariance analysis. Inositol is not metabolizable in brain (Sherman 1991), and this argues against postmortem effects as the cause of the finding of reduced frontal inositol levels. Inositol phosphates that could be metabolized to inositol postmortem are present in very small concentrations as compared to inositol (Sherman 1991) and are unlikely to be able to explain the clinical difference. These brain samples have also been studied for other biochemical factors (HK Manji, personal communication) including $G$ protein $\alpha$ subunits and PKC isozymes, especially the PKC $\gamma$, which is sensitive to proteolytic degradation, and have been found to have robust levels compared with rat cortex, with no correlation with PMI and no suggestion of postmortem degradation.

High-dose acute $\mathrm{Li}$ is reported to lower inositol in rat brain cortex, but therapeutically equivalent acute doses or chronic Li have smaller and less consistent effects (Sherman et al. 1985a). Therapeutic doses of Li lower cortical inositol by about at most $10 \%$, and toxic doses by at most about 30\% (Agam et al. 1994). Thus, Li overdoseage is not the likely cause of the $25 \%$ reduction of frontal cortical inositol in these patients.

The pathophysiological implications of low frontal cortex inositol are unclear. Phosphatidylinositol (PI) synthase may not be saturated at physiological levels of $10 \mathrm{mM}$ inositol (Ghalayini and Eichberg 1985). Several intracellular pools of inositol may exist (Bersudsky et al.

\section{POSSIBLECONSEQUENCES OF REDUCED INOSITOL LEVELS}

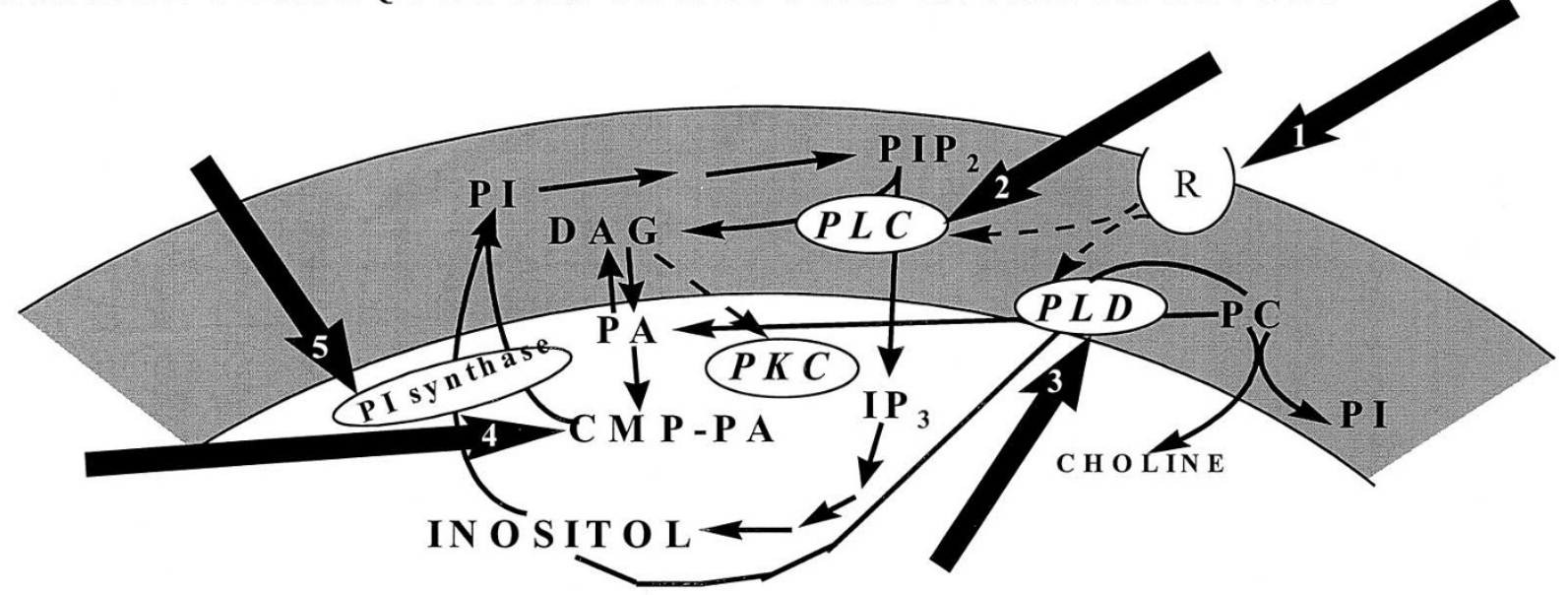

$\stackrel{----\rightarrow}{\longrightarrow} \quad \begin{aligned} & \text { effect } \\ & \longrightarrow\end{aligned}$

Figure 4. Description of the sites of possible effect of reduced inositol levels (depicted by the bold arrows) according to their numbers: 1. In the absence of exogenous inositol, 5-HT induces heterologous desensitization of the facilitated NMDA depolarization in response to 5-HT agonists (Rahman and Neuman 1993); suggested mechanism: receptor sequestration; 2. In systems with low inositol level, coupling of PLC and PI synthase stimulation is controlled by intracellular inositol concentration. Depletion of inositol attenuates accelerated PI resynthesis driven by agonist-activation of PLC (Batty and Downs 1995); 3 (a). In response to agonists, in addition to PI hydrolysis by PLC, PLD cleaves PC to produce PA, which is dephosphorylated to DAG (Nishizuka 1992); (b) PLD also exchanges the choline moiety in PC with free inositol to produce PI, which may be further cleaved by PLC to produce more DAG. Inositol depletion may attenuate these pathways, decrease DAG levels, resulting in deficient PKC activation; 4 . Reduced inositol levels result in increased CMP-PA accumulation because of a deficiency in inositol available to combine with CMP-PA (Godfrey 1989), which may lead to DAG accumulation and subsequent PKC desensitization; 5 (a) In cells with low inositol levels, PI synthase is possibility unsaturated (Km for inositol $4.6 \mathrm{mM}$, Ghalayini and Eichberg 1985), decreasing PI levels; (b) Reduced inositol levels may relieve repressed gene expression of INO1 (inositol-1-P synthase) and FAS 1 and FAS $_{2}$ (fatty acid synthase) via ICRE (inositol/choline responsive elements) existing in yeast genes (Lopes and Henry 1991; Schuller et al. 1992) resulting in elevated PI resynthesis; this may also exist in mammals. 
1994), and the reduction in frontal cortex may be specific to a pool critical for neuronal second messenger function. Batty and Downes $(1994,1995)$ have reported that coupling of PLC and PI synthase requires high enough inositol levels. If "normal" inositol levels do regulate PI concentration and phospholipase $\mathrm{C}$ activity, which breaks down PI in response to receptor stimulation, then low inositol levels could cause functionally deficient responses to one or more receptors linked to PI.

Inositol functions as an important brain osmolyte (Thurston et al. 1989) as well as a second messenger precursor. Hyponatremia lowers brain inositol, and if suicides or affective patients were more likely to be hyponatremic for several days before death than normals, this could artifactually lower brain inositol in the nonneurotransmitter-related pool. Agonal diseases (Hardy et al. 1985) in these patients cannot be ruled out as a cause of the finding. Diabetic ketoacidosis (Kreis and Moss 1992) and Alzheimer's disease (Miller et al. 1993) have been reported to raise brain inositol. Hepatic encephalopathy markedly reduces brain inositol (Haussinger et al. 1994). Postmortem brain studies have inherent methodological limitations (Palmer et al. 1988). Brain inositol may be measured in vivo by magnetic resonance spectroscopy (MRS). Gruetter et al. (1992) and Deicken et al. (1995) have reported phosphomonoester data consistent with our postmortem findings.

\section{CONCLUSION}

Inositol is a simple compound present in high concentration in brian, and it is difficult in this age of increasing specificity of receptor-active psychotropics, for many psychopharmacologists to see it as a potential therapeutic mechanism. However, L-dopa was similarly difficult to accept as a precursor requiring gram dosages for effectiveness, and it is still not clear how exogenous L-dopa is therapeutic in Parkinson's disease, where cell death leads to massive changes in specific innervation. The fact that lithium lowers inositol and bipolar patients have low frontal cortical inositol would seem to be a self-contradictory hypothesis. However, Figure 4 illustrates several different points in the PI cycle where Li-induced decrease in inositol levels or psychopathology-associated reduction in inositol levels could affect the functioning of the cycle. The effects are complex and could be opposing in different brain areas, in different subcellular compartments, and under different baseline conditions.

\section{ACKNOWLEDGMENTS}

We thank the numerous collaborators on various aspects of our inositol studies: Hady Shimon, B.Sc., Yardena Patishi,
M.Sc., Yuli Bersudsky, M.D., Ph.D., Beate Lubrich, M.Sc., Ellena Sobelev, M.Sc., Joseph Shapiro, M.D., Ph.D., and Joseph Levine, M.D. We thank Ellana Shellem for typing and editorial assistance. We thank Joel Kleinman and Thomas Hyde for human brain samples from their collection. We also thank William R. Sherman of Washington University, St. Louis, MO for his unstinting encouragement, advice, and support of inositol studies in Beersheva. This research was partially supported by a grant from the Stanley Foundation to Galila Agam, Ph.D. and a GIF grant No I-245-098.02/92 to Ora Kofman PhD., R.H. Belmaker, M.D., and Dietrich van Calker, M.D., Ph.D

\section{REFERENCES}

Agam G, Livne A (1989): Inositol-1-phosphatase of human erythrocytes is inhibited by therapeutic $\mathrm{Li}^{+}$concentrations. Psychiat Res 27:217-224

Agam G, Shapiro J, Bersudsky Y, Kofman O, Belmaker RH (1994): Effect of high-dose peripheral inositol: Brain inositol levels and prevention of behavioral changes due to inositol depletion. Pharmacol Biochem Behav 49:341-343

Allison JH, Stewart MA (1971): Reduced brain inositol in lithium-treated rats. Nature 233:267-268

Allison JH, Blisner ME, Holland WM, Hipps PP, Sherman WB (1976): Increased myo-inositol-1-phosphate in lithium-treated rats. Biochem Biophys Res Comm 71:664670

Allison JH, Boshans RL, Hallcher LM, Packman PM, Sherman WR (1980): The effects of lithium on myo-inositol levels in layers of frontal cerebral cortex, in cerebellum, and in corpus callosum in rats. J Neurochem 34:456-458

Barkai IA, Dunner DL, Gross HA, Mayo P, Fieve RR (1978): Reduced myo-inositol levels in cerebrospinal fluid from patients with affective disorder. Biol Pyschiatr 13:65-72

Batty IH, Downes CP (1994): The inhibition of phosphoinositide synthesis and muscarinic-receptor-mediated phospholipase $\mathrm{C}$ activity by $\mathrm{Li}^{+}$as secondary, selective, consequences of inositol depletion in $1321 \mathrm{~N} 1$ cells. Biochem J 297:529-537

Batty IH, Downes CP (1995): The mechanisms of muscarinic receptor-stimulated phosphatidylinositol resynthesis in $1321 \mathrm{~N} 1$ astrocytoma cells and its inhibition by $\mathrm{Li}^{+}$ions. J Neurochem 65:2279-2289

Benjamins JA, Agranoff BW (1969): Distribution and properties of CDP-diglyceride:inositol transferase from brain. J Neurochem 16:513-527

Bersudsky Y, Shapiro J, Agam G, Kofman O, Belmaker RH (1994): Behavioral evidence for the existence of two pools of cellular inositol. Euro Neuropsychopharmacol 4:463-467

Busa WB, Gimlich RL (1989): Lithium-induced teratogenesis in frog embryos prevented by a polyphosphoinositide cycle intermediate or a diacylglycerol analog. Dev Biol 132:315-324

Deicken RF, Fein G, Weiner MW (1995): Abnormal frontal lobe phosphorus metabolism in bipolar disorder. Am J Psychiatr 152:915-918

Dixon JF, Los GV, Hokin LE (1992): Lithium enhances accumulation of $\left[{ }^{3} \mathrm{H}\right]$ inositol radioactivity and mass of sec- 
ond messenger inositol 1,4,5-triphosphate in monkey cerebral cortex slices. J Neurochem 59:2332-2335

Fain JN, Berridge MJ (1979): Relationship between phosphatidyl-inositol synthesis and recovery of 5-hydroxytryptamine-responsive $\mathrm{Ca}^{2+}$ flux in blowfly salivary glands. Biochem J 180:661-665

Ghalayini A, Eichberg J (1985): Purification of phosphatidylinositol synthetase from rat brain by CDP-diacylglycerol affinity chromatography and properties of the purified enzyme. J Neurochem 44:175-182

Godfrey PP (1989): Potentiation by lithium of CMP-phosphatidate formation in carbachol-stimulated rat cerebral-cortical slices and its reversal by myo-inositol. Biochem J 258:621-624

Gruetter R, Rothman DJ, Novotny EJ, Shulman RG (1992): Localized ${ }^{13} \mathrm{C}$ NMR spectroscopy of myo-inositol in human brain in vivo. Mag Res Med 25:204-210

Hallcher LM, Sherman WR (1980): The effect of lithium ion and other agents on the activity of myo-inositol-1-phosphatase from bovine brain. J Biol Chem 255:10896-10901

Hardy JA, Wester P, Winblad B, Gezelius C, Bring G, Eriksson A (1985): Patients dying after long terminal phase have acidotic brains: Implications for biochemical measurements on autopsy tissue. J Neural Transm 61:253-264

Haussinger D, Laubenberger J, Dahl V, Ernst T, Bayer S, Langer M, Gerok W, Hennig J (1994): Proton magnetic resonance spectroscopy studies on human brain myoinositol in hypo-osmolarity and hepatic encephalopathy. Gastroenterology 107:1475-1480

Hirvonen MR, Savolainen K (1991): Lithium-induced decrease of brain inositol and increase of brain inositol-1-phosphate is transient. Neurochem Res 16:905-911

Honchar MP, Olney JW, Sherman WR (1983): Systemic cholinergic agents induce seizures and brain damage in lithium-treated rats. Science 220:323-325

Honchar MP, Ackerman KE, Sherman WR (1989): Chronically administered lithium alters neither myo-inositol monophosphatase activity nor phosphoinositide levels in rat brain. J Neurochem 53: 590-594

Inhorn RC, Majerus PW (1987): Inositol and polyphosphate 1-phosphatase from calf brain. Purification and inhibition of $\mathrm{Li}^{+}, \mathrm{Ca}^{2+}$, and $\mathrm{Mn}^{2+}$. J Biol Chem 262:15946-15952

Jope RS, Williams MB (1994): Lithium and brain signal transduction systems. Biochem Pharmacol 47:429-441

Kofman O, Klein E, Newman M, Hamburger R, Kimche O, Nir T, Shimon H, Belmaker RH (1990): Inhibition by antibiotic tetracyclines of rat cortical noradrenergic adenylate cyclase and amphetamine-induced hyperactivity. Pharmacol Biochem Behav 37:417-424

Kofman O, Belmaker RH (1993): Biochemical, behavioral, and clinical studies of the role of inositol in lithium treatment and depression. Biol Psychiatr 34:839-852

Kofman O, Sherman WR, Katz V, Belmaker RH (1993): Restoration of brain myo-inositol levels in rats increases latency to lithium-pilocarpine seizures. Psychopharmacology 110:229-234

Kreis R, Moss BD (1992): Cerebral metabolic disturbances in patients with subacute and chronic diabetes mellitus: detection with proton MR spectroscopy. Radiology 184:123-130.
Levine J, Gonsalves M, Barbam I, Stier S, Elizur A, Kofman O, Belmaker RH (1993): Inositol 6 gm daily may be effective in depression but not in schizophrenia. Human Psychopharmacol 8:49-53

Levine J, Barak Y, Gonsalves M, Szor H, Elizur A, Kofman O, Belmaker RH (1995): A double-blind controlled trial of inositol treatment of depression. Am J Psychiatr 152: 792-794

Lopes JM, Henry SA (1991): Interaction of trans and cis regulatory elements in the IN01 promoter of Saccharomyces cerevisaae. Nuc Acids Res 14:3987-3994

Lowry OH, Rosenbrough ND, Farr AL, Randall RJ (1951): Protein measurement with the folin-phenol reagent. J Biol Chem 193:265-275

Lubrich B, Patishi Y, Kofman O, Agam G, Berger M, Belmaker RH, van Calker D (1997): Lithium-induced inositol depletion in rat brain after chronic treatment is restricted to the hypothalamus. Mol Psychiatr 2:407-412

Mason R, Biello SM (1992): A neurophysiological study of a lithium-sensitive phosphoinositide system in the hamster suprachiasmatic (SCN) biological clock in vitro. Neurosci Lett 144:135-138

Miller BL, Moats RA, Shonk T, Ernst T, Woolley S, Ross BD (1993): Alzheimer disease: Depiction of increased cerebral myo-inositol with proton MR spectroscopy. Radiology 187:433-437

Moscovich D, Belmaker RH, Agam G, Livne A (1990): Inositol-1-phosphatase in RBC of manic-depressive patients before and during treatment with lithium. Biol Psychiat 27:552-555

Murphy DL, Belmaker RH, Carpenter WT, Wyatt RJ (1977): Monoamine oxidase in chronic schizophrenia: Studies of hormonal and other factors affecting enzyme activity. Brit J Psychiat 130:151-158

Nahorski SR, Ragan CI, Challiss RA (1991): Lithium and the phosphoinositide cycle: An example of uncompetitive inhibition and its pharmacological consequences. Trends Pharmacol Sci 12:297-303

Nishizuka Y (1992): Intracellular signaling by hydrolysis of phospholipids and activation of protein kinase C. Science 258:607-614

Palmer AM, Lowe SL, Francis PT, Bowen DM (1988): Are post-mortem biochemical studies of human brain worthwhile? Biochem Soc Trans 16:472-475

Patel S, Meldrum BS, Fine A (1988): Susceptibility to pilocarpine-induced seizures in rats increases with age. Behav Brain Res 31:165-167

Patishi Y, Belmaker RH, Agam G (1996a): Effect of age, sex, steroids, brain region, and genetic strain on brain inositol monophosphatase activity. Biol Psychiat 40:656-659

Patishi Y, Belmaker RH, Bersudsky Y, Kofman O (1996b): A comparison of the ability of myo-inositol and epi-inositol to attenuate lithium-pilocarpine seizures in rats. Biol Psychiat 39:829-832

Patishi Y, Lubrich B, Berger M, van Calker D, Kofman O, Belmaker RH (1996c): Differential uptake of myo-inositol in vivo into rat brain areas. Eur Neuropsychopharmacol 6:73-75

Rahman S, Neuman RS (1993): Myo-inositol reduces seroto$\operatorname{nin}\left(5-\mathrm{HT}_{2}\right)$ receptor induced homologous and heterologous desensitization. Brain Res 631:349-351 
Richards MH, Belmaker RH (1996): Epi-inositol is biochemically active in reversing lithium effects on cytidine monophosphorylphosphatidate (CMP-PA). J Neural Transm 103:1281-1285

Schuller JH, Hahn A, Troster F, Schutz A, Schweizer E (1992): Coordinate genetic control of yeast fatty acid synthase genes FAS1 and FAS2 by an upstream activation site common to genes involved in membrane lipid biosynthesis. EMBO J 11:107-114

Sherman WR, Leavitt AL, Honchar MP, Hallcher LM, Phillips BE (1981): Evidence that lithium alters phosphoinositide metabolism: Chronic administration elevates primarily D-myo-inositol-1-phosphate in cerebral cortex of the rat. J Neurochem 36:1947-1951

Sherman WR, Honchar MP, Munsell LY (1985a): Detection of receptor-linked phophoinositide metabolism in brian of lithium-treated rats. In Bleasdale JE, Eichborg J, Hauser C (eds), Inositol and Phosphoinositides: Metabolism and Regulation. Clifton NJ, Humana Press, pp 49-65

Sherman WR, Munsell LY, Gish BG, Honchar MP (1985b): Effects of systemically administered lithium on phosphoinositide metabolism in rat brain, kidney and testis. J Neurochem 44:798-807

Sherman WR, Gish BG, Honchar MP, Munsell LY (1986): Effects of lithium on phoshoinositide metabolism in vivo. Fed Proc 45:2639-2646

Sherman WR (1991): Lithium and the phosphoinositide signalling system. In Birch NJ (ed), Lithium and the Cell: Pharmacology and Biochemistry. London, Academic Press, pp 121-157
Shimon H, Agam G, Belmaker RH, Hyde T, Kleinman JE (1997): Reduced inositol levels in frontal cortex of postmortem brain from bipolar patients and suicides. Am J Psychiatry 154:1148-1150

Spector R, Lorenzo AV (1975): Myo-inositol transport through the blood-brain barrier. Neurochem Res 13:785-787

Taussky H, Shorr E, Kurzmann GA (1953): A microcolorimetric method for the determination of inorganic phosphorus. J Biol Chem 20:675-681

Thurston JH, Sherman WR, Hauhart RE, Kloepper RF (1989): Myo-inositol: A newly identified nonnitrogenous osmoregulatory molecule in mammalian brain. Pediatr Res 26:482-485

Tricklebank MD, Singh L, Oles RJ (1991): Evidence that a proconvulsant action of lithium is mediated by inhibition of myo-inositol phosphatase in mouse brain. Brain Res 558:145-148

Whitworth P, Kendall DA (1989): Effects of lithium on inositol phospholipid hydrolysis and inhibition of dopamine D1 receptor-mediated cyclic AMP formation by carbachol in rat brain slices. J Neurochem 53:536-541

Williams MB, Jope RS (1995): Modulation by inositol of cholinergic- and serotonergic-induced seizures in lithium treated rats. Brain Res 685:169-178

Wood AJ, Goodwin GM (1987): A review of the biochemical and neuropharmacological actions of lithium. Psychol Med 17:579-600

Zilberman-Kaufman M, Agam G, Moscowitz L, Livne AA, Belmaker RH (1992): Raised monophosphatase activity in schizophrenic patients. Clin Chim Acta 209:89-93 